\title{
Structural Change of Apoferritin as the Effect of pH Change: DLS and SANS Study
}

\author{
Arum Patriati ${ }^{1{ }^{*}}$, Nadi Suparno ${ }^{1}$, Grace Tjungirai Sulungbudi ${ }^{1}$, Mujamilah Mujamilah $^{1}$, and Edy Giri \\ Rachman Putra ${ }^{2}$ \\ ${ }^{1}$ Center for Science and Technology of Advanced Materials, National Nuclear Energy Agency, Puspiptek Area Serpong, \\ Tangerang Selatan 15310, Indonesia \\ ${ }^{2}$ Polytechnic Institute of Nuclear Technology, National Nuclear Energy Agency, \\ Jl. Babarsari Kotak POB 6101/YKKB, Yogyakarta, Indonesia
}

${ }^{*}$ Corresponding author:

tel: $+62-85643516165$

email:arum@batan.go.id

Received: October 16, 2019

Accepted: December 17, 2019

DOI: $10.22146 /$ ijc. 50630

\begin{abstract}
Apoferritin is a complex protein potential for drug delivery application. The advantage of apoferritin lies in its core-shell structure, its nano size, and its $p H$-sensitivity. This study was aimed to characterize the structure of apoferritin due to the $\mathrm{pH}$ alteration effect in a solution using dynamic light scattering (DLS) and small-angle neutron scattering (SANS). Both DLS and SANS can observe protein size in solution near its physiological condition. The results show that apoferritin possesses a core-shell structure with a diameter of around 12-13 $\mathrm{nm}$ at $\mathrm{pH}$ 7. The dissociation of apoferritin occurs at $p H$ 1.9. The SANS data shows the apoferritin at $p H 1.9$ was dissociated into the smaller oligomer. The structure of this smaller oligomer has a different configuration than the configuration of apoferritin subunits at $\mathrm{pH}$ 7. It can cause the failure of reassembly of apoferritin if the apoferritin is neutralized back to $\mathrm{pH} 7$ after dissociation from $\mathrm{pH}$ 1.9.
\end{abstract}

Keywords: apoferritin; dissociation; $p H$ change; SANS; DLS

\section{- INTRODUCTION}

Ferritin is a core-shell complex protein that has a role in iron storage and detoxification in mammalian and maintains the iron excess in the body [1-2]. Without iron inside, ferritin is called apoferritin. The inner space of apoferritin can be used to transport some organic or inorganic compounds in the body. Apoferritin is nontoxic, biodegradable, and biocompatible in the body, has a nano-size inner core, and high thermal stability [3-4]; thus, promising for a drug delivery application. Moreover, the apoferritin structure has a sensitivity to $\mathrm{pH}$ conditions, which can be used to develop a controlled released drug delivery system [5-6].

Apoferritin dissociates into its monomers at $\mathrm{pH} 2$ and can reversibly associate in neutral $\mathrm{pH}$, which is used to encapsulate a cancer drug called doxorubicin [7]. However, a native-PAGE test of apoferritin and apoferritin-doxorubicin at $\mathrm{pH} 4$ and $\mathrm{pH} 7$ showed that the molecular weight for both remained the same after the dissociation process through $\mathrm{pH} 2$. The molecular weight data of the native-PAGE test did not show the mechanism of the dissociation itself.

This work will observe the structural change of the apoferritin in various $\mathrm{pH}$ using dynamic light scattering (DLS) and small-angle neutron scattering (SANS). Analysis of protein using DLS allows us to know the general size of protein in solution via its dynamic light scattering characteristic [8-10]. Meanwhile, SANS analysis will give more detail about the low-resolution threedimensional structure of the protein in the solution based on the small-angle scattering phenomenon. The observation of protein structure in the solution provides important information to reveal its structure near its native condition [11]. Therefore, the structural change of apoferritin regarding its dissociation-association properties can be better understood.

\section{- EXPERIMENTALSECTION}

\section{Materials}

Apoferritin in $25 \mathrm{mg} / \mathrm{mL}$ saline solution (no. A3641) 
and deuterium oxide $/ \mathrm{D}_{2} \mathrm{O}$ (no. 151882) were purchased from Sigma-Aldrich. Potassium dihydrogen phosphate $/ \mathrm{KH}_{2} \mathrm{PO}_{4}$ (no. 104873), potassium hydrogen phosphate $/ \mathrm{K}_{2} \mathrm{HPO}_{4}$ (no. 105104), sodium chloride $/ \mathrm{NaCl}$ (no. 106400), and hydrochloride acid/HCl (no. 100317) were purchased from Merck. All chemicals were used without further purification.

\section{Instrumentation}

Dynamic Light Scattering (DLS) measurements were carried out using Particle Size Analyzer (Zetasizer Nano ZS-Malvern) with light of wavelength $633 \mathrm{~nm}$. This instrument provides the ability to measure particle size and zeta potential of particles or molecules in a liquid medium. The Zetasizer system determines the size by measuring the Brownian motion of the particles in a sample. The fundamental principle is that small particles move more quickly in a liquid than larger particles. Therefore, measuring the Brownian motion of particles or molecules, it can interpret their size.

Small Angle Neutron Scattering (SANS) measurements were carried out using the SANS BATAN spectrometer [12]. SANS is a technique which utilizes the scattered neutron from particles or molecules in small angle region. The neutron scattering data provides information about size, distribution of particles or molecules in 1-100 nm. Since neutron can deeply penetrate into material, SANS can measure any form of sample such as gel, liquid or solid.

\section{Procedure}

\section{Sample preparation}

Apoferritin was dialyzed in $\mathrm{K}_{2} \mathrm{HPO}_{4}-\mathrm{KH}_{2} \mathrm{PO}_{4}$ buffer ( $\mathrm{pH} 7.4$ ) for $24 \mathrm{~h}$ as an apoferritin native state. Apoferritin in $\mathrm{pH} 1.9$ was prepared by dialyzed it in a $\mathrm{KCl}-\mathrm{HCl}$ buffer for $24 \mathrm{~h}$. The apoferritin for the DLS experiment was dissolved in $\mathrm{H}_{2} \mathrm{O}$. Meanwhile, for SANS, the apoferritin was dissolved in $\mathrm{D}_{2} \mathrm{O}$ to gain contrast match.

\section{DLS measurement}

The DLS measurements were conducted by set the detector at $173^{\circ}$ in order to avoid the direct beam scattering interference. All samples were measured at room temperature.

\section{SANS measurement}

All samples were measured using neutron with a wavelength of $3.9 \AA$ at room temperature. Each measurement was conducted at two detector positions, i.e., at $2 \mathrm{~m}$ for $8 \mathrm{~h}$ and $6 \mathrm{~m}$ for $20 \mathrm{~h}$. This configuration was set to cover q range from $0.01 \AA^{-1}$ to $0.2 \AA^{-1}$. All measured samples were corrected from its background and electronic noise.

Experimental scattering data were corrected with GRASP [13] and analyzed with Igor SANS Analysis [14]. The ab initio molecular shape determination programs GNOM, DAMMIF, and DAMAVER [15] were used to reconstruct molecular shapes of the proteins in solution. This reconstruction undergoes the Fourier-transform calculation and gains the pair distribution function of the small-angle neutron scattering data. The pair distribution function represents the distribution of each pair scattering body in the protein. Furthermore, the threedimensional model of the protein can be reconstructed.

\section{- RESULTS AND DISCUSSION}

Apoferritin consists of 24 protein subunits arranged in several symmetries to create a core-shell structure with eight hydrophilic channels from threefold symmetry and six hydrophobic channels from fourfold symmetry [16]. The interactions between all of its protein subunits are physical interaction without any chemical covalent bonding [17]. Due to its subunits interaction, the stability of the apoferritin structure depends on its environment, such as $\mathrm{pH}$ conditions. DLS experimental data of apoferritin at $\mathrm{pH} 7$ show a sharp peak on $13 \mathrm{~nm}$ (Fig. 1). The peak was observed to be shifted to $7 \mathrm{~nm}$ when the environment of apoferritin is set to an acidic solution at $\mathrm{pH}$ 1.9. This data indicated that the apoferritin had been dissociated into a smaller part of its oligomer. When the solution becomes acidic (at $\mathrm{pH} 2$ or lower), the protonation occurs in the carboxyl group at the surface of the apoferritin [18]. The protonation disturbs the stability of the tertiary structure of the subunits through the stability of the whole apoferritin core-shell structure. The protonation to carboxyl groups goes further to the hydroxyl group at tryptophan residue, which has an important role in the 


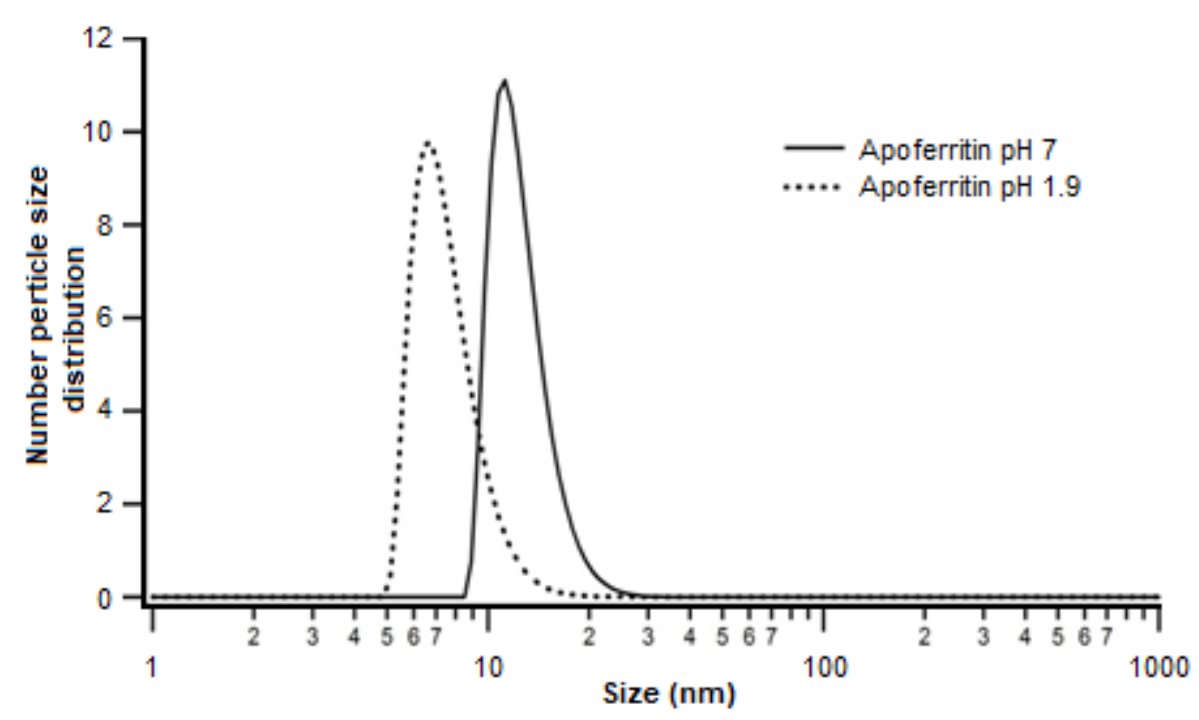

Fig 1. DLS data of the apoferritin size at pH 7 (solid line) and pH 1.9 (dot line)

hydrophobic channel structure [18]. As the hydroxyl group is being exposed by solution, it gives the dissociation effect for the apoferritin.

The alteration of the hydroxyl group, which has a role on the hydrophobic channel, break the four-fold symmetry of the apoferritin. The break of interaction between subunits in this four-fold symmetry initiated the dissociation of the apoferritin into the smaller part. This smaller part of the apoferritin was confirmed by DLS measurement from the decreasing of the particle size shown in Fig. 1.

The dissociation of apoferritin in acidic solution was also confirmed by SANS. The SANS scattering profile of apoferritin at $\mathrm{pH} 7$ shows the typical ripple of the coreshell structure (Fig. 2). Data analysis using a spherical core-shell model with Igor SANS Analysis results in the core size of apoferritin of $7.98 \mathrm{~nm}$ and the shell thickness of $2.06 \mathrm{~nm}$, suggesting that the overall diameter of apoferritin is $12.1 \mathrm{~nm}$, which are coincided with the DLS data. The analysis of apoferritin at $\mathrm{pH} 1.9$ was well-fitted with the triaxial ellipsoid model and gained 1.2, 3.5, and $6.7 \mathrm{~nm}$ for the three-axis of the ellipsoid.

Further analysis of the SANS scattering profile was conducted to construct the three-dimension lowresolution model of the apoferritin at $\mathrm{pH} 7$ and $\mathrm{pH}$ 1.9. The SANS scattering data were Fourier-transformed into pair distribution function as the real space function from SANS scattering data. The pair distribution function expresses the distance of each scattering body (r) of the apoferritin and the probability of each value. This analysis was done using the GNOM program. The information on the distribution of the $\mathrm{r}$ values extracted from the function in the GNOM is then modeled into three-dimensional form. The reconstruction of threedimensional models from the data is built by dummy atoms and a dummy particle with a volume using DAMMIF and DAMAVER program. The program will arrange the dummy atoms in a certain position and volume based on the pair distribution function.

The pair distribution function of the apoferritin at pH 7 and pH 1.9 show that $D_{\max }$ of the apoferritin is larger at $\mathrm{pH} 7$ than at $\mathrm{pH} 1.9$ (Fig. 2(c)). Since the $\mathrm{D}_{\max }$ in pair distribution function represents the longest distance of the two-scattering body, it indicates that apoferritin was disassembled in an acidic solution. Apoferritin at neutral $\mathrm{pH}(\mathrm{pH} 7)$ has $\mathrm{D}_{\max }$ of $12 \mathrm{~nm}$ and decreases to $7 \mathrm{~nm}$ at $\mathrm{pH}$ 1.9. The $\mathrm{D}_{\max }$ of apoferritin at $\mathrm{pH} 7$ represents the apoferritin core-shell structure diameter, while at $\mathrm{pH} 1.9$, the $\mathrm{D}_{\max }$ represents the longest distance of its structure.

The three-dimensional structure of the apoferritin at $\mathrm{pH} 7$ and $\mathrm{pH} 1.9$ generated by the DAMMIF program and visualized by pyMOL [19-20] are shown in Fig. 3 and Fig. 4, respectively. The three-dimensional model structure of the apoferritin at $\mathrm{pH} 7$ corresponds with the other work [16-17,21]. 

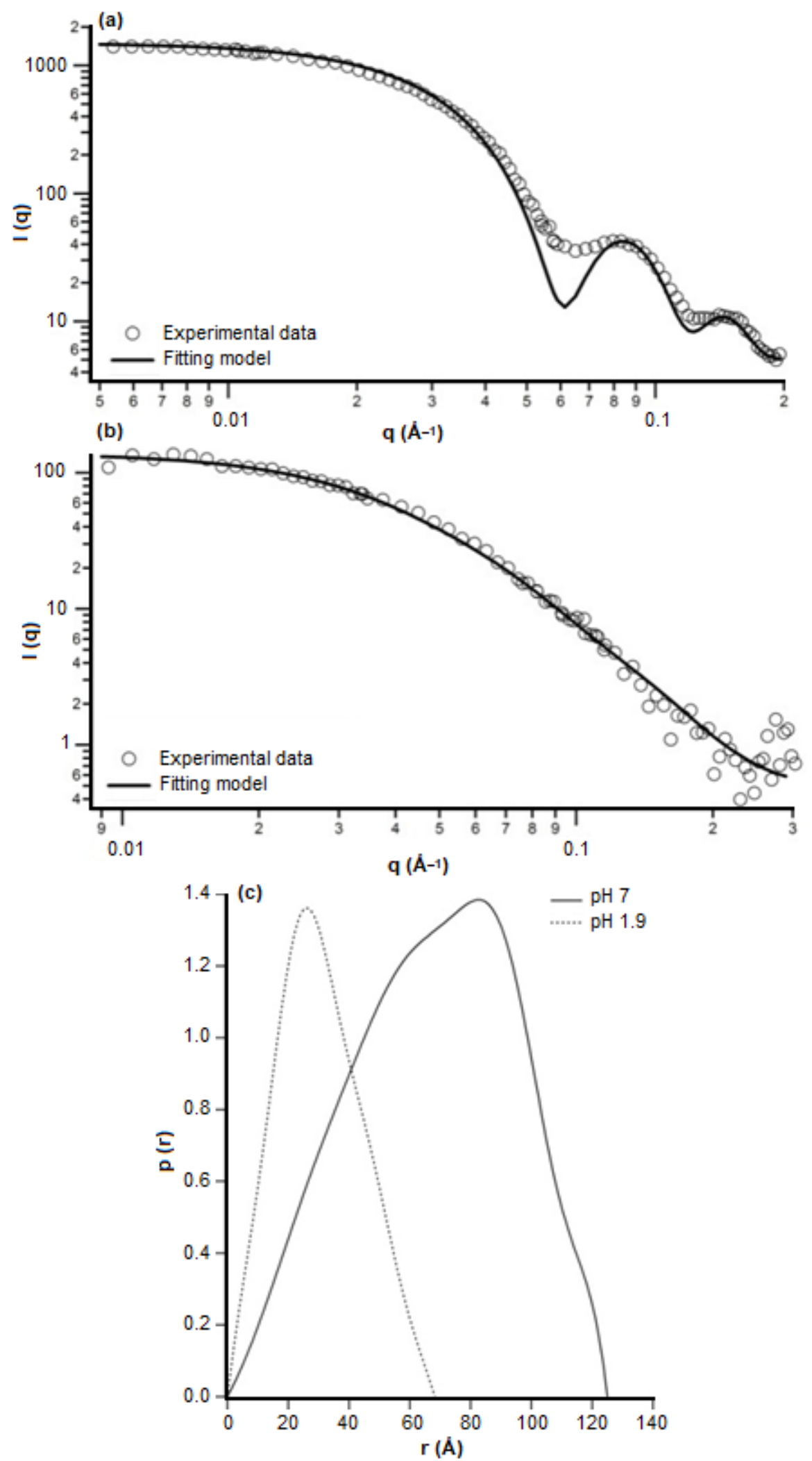

Fig 2. SANS scattering profile of apoferritin at (a) $\mathrm{pH}$ 7and (b) $\mathrm{pH}$ 1.9. (c) The pair distribution function of apoferritin at $\mathrm{pH} 7$ and $\mathrm{pH} 1.9$ 

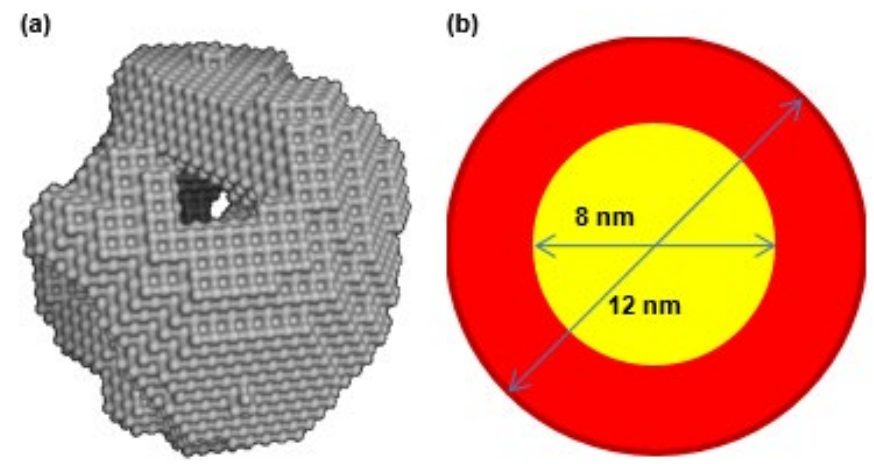

Fig 3. (a) The three-dimensional model of apoferritin at $\mathrm{pH} 7$ generated by DAMMIF and visualized by pyMOL and (b) the core-shell model based on Igor SANS analysis data
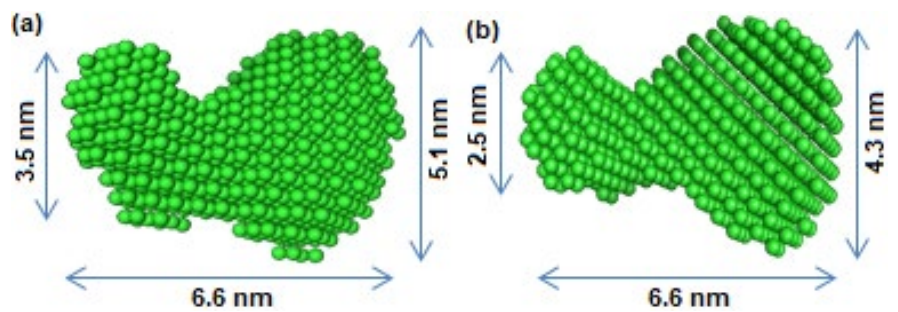

Fig 4. The three-dimensional model of apoferritin at $\mathrm{pH}$ 1.9 based on SANS data from (a) side view and (b) top view after $90^{\circ}$ rotation

The core-shell structure of the apoferritin is disrupted at acid condition, which is depicted in its threedimensional model. The molecular weight of the dissociated apoferritin at $\mathrm{pH} 1.9$ cannot be confirmed since the SANS data is not analyzed by absolute scale. However, the model generated from SANS is still reliable as the structure of protein depends on the profile of the neutron scattering intensity at certain scattering vector (q).

The $\mathrm{R}_{\mathrm{g}, \mathrm{p}(\mathrm{r})}$ of apoferritin at $\mathrm{pH} 7$ is $5.25 \mathrm{~nm}$, while the $\mathrm{R}_{\mathrm{g} p \mathrm{p}(\mathrm{r})}$ of apoferritin at $\mathrm{pH} 1.9$ is $3.66 \mathrm{~nm}$. This result is similar to the $\mathrm{R}_{\mathrm{g}, \mathrm{p}(\mathrm{r})}$ of apoferritin at $\mathrm{pH} 1.9$ and $\mathrm{pH} 7$ that was reported by Kim et al. [22]. However, the threedimensional structure of apoferritin at $\mathrm{pH} 1.9$ is not consistent with the one proposed in Ref. 22. In this work, the three-dimensional model of apoferritin at $\mathrm{pH} 1.9$ shows the smaller part of instead of maintains its diameter with semi-circle structure which is showed in Ref. 22. This dissociation is due to the protonation of the apoferritin to its four-fold symmetry subunits. They exist at six positions in all around of the apoferritin core-shell structure. Therefore, the alteration of those sites at a very rich proton condition, $\mathrm{pH}$ 1.9, makes the apoferritin dissociated into the smaller oligomer.

The dimension of the small oligomer of the apoferritin at $\mathrm{pH} 1.9$ obtained by SANS data analysis is about three times of its monomer (PDB:5erk) [23]. As the SANS analysis is not conducted by absolute intensity mode, this dimension does not represent its molecular weight. Therefore, it cannot conclude the number of subunits in this small oligomer. However, the arrangement of the apoferritin subunits oligomer at $\mathrm{pH}$ 1.9 is different with four-fold, three-fold or four-fold symmetry in its core-shell oligomer at $\mathrm{pH}$ 7. It indicates that the protonation induces the disruption of the tertiary structure of the apoferritin subunit and changes its configuration. Furthermore, it can cause failure in the reassembly of the apoferritin from acidic to neutral $\mathrm{pH}$. This assumption should be further studied to clarify the reassembly ability of apoferritin from acidic conditions to neutral $\mathrm{pH}$ conditions.

\section{- CONCLUSION}

The data from DLS and SANS revealed the dissociation process of apoferritin as the effect of the change of $\mathrm{pH}$. Instead of being dissociated into its monomers, the dissociation of apoferritin at $\mathrm{pH} 1.9$ was like small oligomers with the dimension of three times of apoferritin's monomer. The three-dimensional structure of this small oligomer, which indicated a configuration change, can cause the failure of apoferritin to reassembly in neutral $\mathrm{pH}$.

\section{- ACKNOWLEDGMENTS}

Authors acknowledge to Nuclear Energy Agency of Indonesia (BATAN) for the funding of this research under research project (DIPA) term 2014-2019.

\section{- REFERENCES}

[1] Bulvik, B.E., Berenshtein, E., Meyron-Holtz, E.G., Konijn, A.M., and Chevion, M., 2012, Cardiac Protection by preconditioning is generated via an iron-signal created by proteasomal degradation of iron proteins, PLoS One, 7 (11), e48947.

[2] Theil, E.C., 2011, Ferritin protein nanocages use ion channels, catalytic sites, and nucleation channels to 
manage iron/oxygen chemistry, Curr. Opin. Chem. Biol., 15 (2), 304-311.

[3] Heger, Z., Skalickova, S., Zitka, O., Adam, V., and Kizek, R., 2014, Apoferritin applications in nanomedicine, Nanomedicine, 9 (14), 2233-2245.

[4] Dostálová, S., Konečná, R., Blažková, I., Vaculovičová, M., Kopel, P., Kř́žková, S., Vaculovič, T., Adam, V., and Kizek, R., 2013, Apoferritin as a targeted drug delivery system, MendelNet 2013, 908-912.

[5] Balamuralidhara, V., Pramodkumar, T.M., Srujana, N., Venkatesh, M.P., Gupta, N.V., Krishna, K.L., and Gangadharappa, H.V., 2011, pH Sensitive drug delivery systems: A review, Am. J. Drug Discovery Dev., 1 (1), 24-48.

[6] Wang, X., Dong, J., Liu, X., Liu, Y., and Ai, S., 2014, A novel $\mathrm{pH}$-controlled immunosensor using hollow mesoporous silica and apoferritin combined system for target virus assay, Biosens. Bioelectron., 54, 85-90.

[7] Kilic, M.A., Ozlu, E., and Calis, S., 2012, A novel protein-based anticancer drug encapsulating nanosphere: Apoferritin-doxorubicin complex, $J$. Biomed. Nanotechnol., 8 (3), 508-514.

[8] Stetefeld, J., McKenna, S.A., and Patel, T.R., 2016, Dynamic light scattering: A practical guide and applications in biomedical sciences, Biophys. Rev., 8 (4), 409-427.

[9] Hawe, A., Hulse, W.L., Jiskoot, W., and Forbes, R.T., 2011, Taylor dispersion analysis compared to dynamic light scattering for the size analysis of therapeutic peptides and proteins and their aggregates, Pharm. Res., 28 (9), 2302-2310.

[10] Li, Y., Lubchenko, V., and Vekilov, P.G., 2011, The use of dynamic light scattering and Brownian microscopy to characterize protein aggregation, Rev. Sci. Instrum., 82 (5), 053106.

[11] Blanchet, C.E., and Svergun, D.I., 2013, Small-angle $\mathrm{X}$-ray scattering on biological macromolecules and nanocomposites in solution, Annu. Rev. Phys. Chem., 64 (1), 37-54.

[12] Putra, E.G.R., Bharoto, and Seong, B.S., 2010, Recent development of a 36 meter small-angle neutron scattering BATAN spectrometer (SMARTer) in Serpong Indonesia, J. Phys. Conf. Ser., 247, 012010.

[13] Dewhurst, C., 2003, GRAS ANS $P$ User Manual, Institut Laue Langevin, Grenoble, France, ILL03DE01T.

[14] Kline, S.R., 2006, Reduction and analysis of SANS and USANS data using IGOR Pro, J. Appl. Crystallogr., 39 (6), 895-900.

[15] Petoukhov, M.V., Franke, D., Shkumatov, A.V., Tria, G., Kikhney, A.G., Gajda, M., Gorba, C., Mertens, H.D.T., Konarev, P.V., and Svergun, D.I., 2012, New developments in the ATSAS program package for small-angle scattering data analysis, $J$. Appl. Crystallogr., 45 (2), 342-350.

[16] Uchida, M., Kang, S., Reichhardt, C., Harlen, K., and Douglas, T., 2010, The ferritin superfamily: Supramolecular templates for materials synthesis, Biochim. Biophys. Acta, Gen. Subj., 1800 (8), 834-845.

[17] Zhang, Y., and Orner, B.P., 2011, Self-assembly in the ferritin nano-cage protein superfamily, Int. J. Mol. Sci., 12 (8), 5406-5421.

[18] Crichton, R.R., and Bryce, C.F., 1973, Subunit interactions in horse spleen apoferritin. Dissociation by extremes of pH, Biochem. J., 133 (2), 289-299.

[19] Hagelueken, G., Ward, R., Naismith, J.H., and Schiemann, O., 2012, MtsslWizard: In silico spinlabeling and generation of distance distributions in PyMOL, Appl. Magn. Reson., 42 (3), 377-391.

[20] Baugh, E.H., Lyskov, S., Weitzner, B.D., and Gray, J.J., 2011, Real-time PyMOL visualization for Rosetta and PyRosetta, PLoS One, 6 (8), e21931.

[21] Russo, C.J., and Passmore, L.A., 2015, Ultrastable gold substrates for electron cryomicroscopy, Science, 346 (6215), 1377-1380.

[22] Kim, M., Rho, Y., Jin, K.S., Ahn, B., Jung, S., Kim, H., and Ree, M., 2011, pH-Dependent structures of ferritin and apoferritin in solution: Disassembly and reassembly, Biomacromolecules, 12 (5), 1629-1640.

[23] Pontillo, N., Pane, F., Messori, L., Amoresano, A., and Merlino, A., 2016, Cisplatin encapsulation within the ferritin nanocage: A high-resolution crystallographic study, Chem. Commun., 52 (22), 4136-4139. 